\title{
ONTOGENETIC CHANGES IN THE PROJECTIONS OF NEOCORTICAL NEURONS $^{1}$
}

\author{
G. O. IVY AND H. P. KILLACKEY ${ }^{2}$
}

Department of Psychobiology, University of California, Irvine, California 92717

Received November 2, 1981; Revised January 4, 1982; Accepted January 5, 1982

\begin{abstract}
Developmental changes in the origins of contra- and ipsilateral projections from the rat parietal cortex were examined using the retrograde transport of horseradish peroxidase and of the fluorescent dyes fast blue and nuclear yellow. The aim of the study was to determine the fate of the neurons which send axons through the corpus callosum in the neonatal, but not the young adult, rat.

1. Neurons which project across the corpus callosum at postnatal day 8 (PND 8), but not at PND 20 or later, do not die; they merely lose their contralateral processes.

2. At PND 8, many of these neurons-in particular, those in lamina Va of the barrel field areaproject simultaneously across the corpus callosum and to the ipsilateral motor cortex.

3. By PND 20 and later, many neurons in lamina $\mathrm{Va}$ of the barrel field area still project to the ipsilateral motor cortex but not across the corpus callosum.
\end{abstract}

We conclude that at least some neocortical neurons initially elaborate more axonal processes than they will maintain and that they selectively eliminate major projections during development.

A major goal of developmental neurobiology is defining the events which underlie the formation of ordered neuronal connections. To date, our understanding of these events is based largely on the study of relationships between the periphery (either receptor or effector) and the central nervous system. Much less is known about the formation of connections in CNS pathways which are not related directly to the periphery. One such CNS pathway which we have been studying is the corpus callosum, a major commissure which interconnects largely symmetric regions of the cerebral neocortices. In the parietal cortex of the adult rat, both the perikarya and the terminal arborizations of callosally projecting neurons are distributed in a discrete fashion. 'They are aligned in vertical arrays in the "agranular" portions of

\footnotetext{
' This research was supported by National Institutes of Health Grant 78-24655. A preliminary report on this work was presented at the 11th Annual Meeting of the Society for Neuroscience in Los Angeles, October, 1981. We wish to express our appreciation to Dr. H. G. J. M. Kuypers for his generosity in providing much of the fast blue used in these experiments and for sharing with us his technical expertise. We are also indebted to Drs. H. Loewe, J. Fallon, and L. Swanson for kindly supplying us with nuclear yellow. Finally, we are grateful to Ms. Susan McKenney for typing the manuscript.

${ }^{2}$ To whom correspondence should be addressed.
}

cortex that surround and interdigitate with the "granular" primary somatosensory cortex, the major recipient of somatic thalamic input (Wise and Jones, 1976, 1978; Akers and Killackey, 1978). Thus, the adult rat parietal cortex can be subdivided generally into regions that send and receive callosal projections and regions that do not. We have reported recently that this heterogeneous organization of adult rat parietal cortex is not present at birth but rather develops during the first 2 postnatal weeks (Ivy et al., 1979; Ivy and Killackey, 1981). During the 1st postnatal week, cells which contribute axons to the corpus callosum are distributed throughout the mediolateral extent of the parietal cortex. Also, these cells have a somewhat wider laminar distribution than is found in the adult rat. During the 2nd postnatal week, there is a gradual and orderly "dropping out" of callosally projecting neurons from the regions destined to be acallosal in the adult. The present experiment concerns the fate of the callosal "drop out" neurons. First, we provide evidence, which confirms the recent report of O'Leary et al. (1981), that these callosal drop out neurons do not die, a point which also has been made in the cat visual cortex (Innocenti, 1981). Second, we provide evidence that some of the neurons which lose their callosal processes maintain a second projection to the ipsilateral motor cortex. 


\section{Materials and Methods}

In order to examine the patterns of neurons in the rat parietal cortex that project to the contralateral and ipsilateral hemispheres, we utilized the retrograde transport of the fluorescent dyes fast blue (FB) and nuclear yellow (NY). These dyes fluoresce blue and yellow, respectively, at an excitation wavelength of $360 \mathrm{~nm}$. A total of 44 rats of various postnatal ages received injections of $\mathrm{FB}$ and/ or NY in either multiple aliquots throughout the parietal cortex of one hemisphere or in a single aliquot in the frontal cortex (MSI, as defined by Hall and Lindholm, 1974). Figure 1 illustrates the various injection paradigms employed in this study and Table I summarizes the precise injection and sacrifice parameters used. A typical ipsilateral injection site is shown in Figure 4. The experiments fall into three major groups: those examining the pattern of contralateral projection cells, those examining the pattern of ipsilateral projection cells, and those examining the patterns of cells projecting to both hemispheres. We have delineated previously the patterns of contralaterally projecting cells in the rat parietal cortex at various postnatal ages using the retrograde transport of horseradish peroxidase (Ivy and Killackey, 1981). We determined that, at postnatal day 7 (PND 7) and earlier, these cells are distributed in a continuous fashion throughout the parietal cortex and that, at PND 15 and later, a more discrete adult pattern is established. Thus, in the present study, we have selected PND 7 as an age to examine the immature pattern and PNDs 20 to 40 as ages to examine the adult pattern of callosal and ipsilateral projection neurons.

First, rats at PND 7 received 20 to 30 small (0.03- to

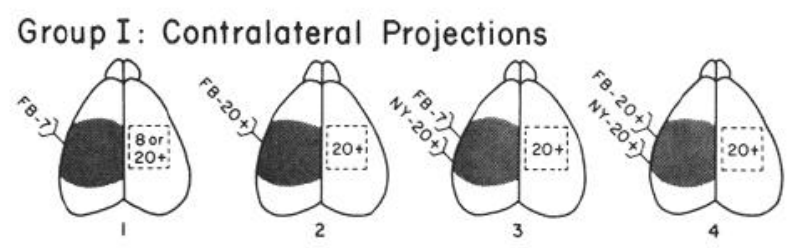

Group II: Ipsilateral Projections
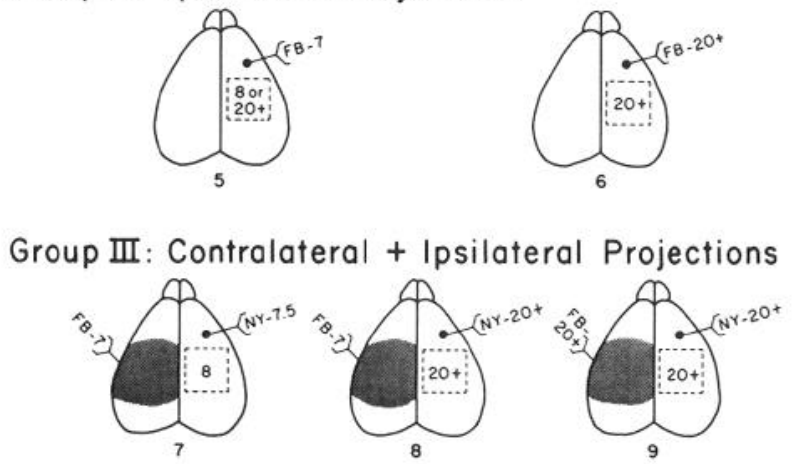

Figure 1. Diagram of dorsal views of the neocortex showing the various experimental paradigms employed in the present study. The large shaded areas represent the contralateral injection site, while the black dots represent the ipsilateral injection site. The type of dye injected and the postnatal age at injection are shown adjacent to each site. In each case, the parietal cortex of the right hemisphere was examined at the postnatal age shown in the square. $0.07-\mu \mathrm{l})$ injections of a $7 \%$ solution of $\mathrm{FB}(\mathrm{w} / \mathrm{v}$ in distilled water) unilaterally throughout the parietal cortex via a micropipette attached to a $1-\mu \mathrm{l}$ Hamilton syringe. Several of these rats were sacrificed on PND 8 to show the continuous immature pattern of callosal projection neurons. The others were sacrificed between PNDs 20 and 25 or on PND 40 to determine if the cells forming the continuous pattern of callosal projection neurons are still present after the time when the more discrete adult pattern is known to have been established. Next, in order to confirm the discrete adult pattern of callosal neurons, rats received small multiple injections of FB unilaterally in the parietal cortex on PND 20 to PND 25 and were sacrificed 36 to $72 \mathrm{hr}$ later. Finally, in order to compare the continuous immature pattern of callosal neurons with the discrete adult pattern in the same animal, 2 rats received multiple injections of $\mathrm{FB}$ unilaterally in the parietal cortex on PND 7 and then received similar injections of NY (5\%, w/v in distilled water) in the same place at PND 21 or 24 . These rats were sacrificed 18 or $22 \mathrm{hr}$ following the NY injection. Thus, if a neuron contained FB, this indicated that it had sent an axon across the corpus callosum at PND 7, and if it contained NY, its axon traversed the corpus callosum at days 21 to 24. In one additional experiment, rats received multiple FB injections contralaterally at PNDs 20 and 25 and then received similar injections of $\mathrm{NY}$ as close as possible to the same sites $24 \mathrm{hr}$ later. The rats were sacrificed 18 or $22 \mathrm{hr}$ after the NY injections. Thus, neurons which project across the callosum at PNDs 20 to 25 should be double labeled with FB and NY and should all be present in the discrete adult pattern.

In the second group of experiments, the pattern of cells in the parietal cortex that project ipsilaterally to the motor cortex was determined with three different retrogradely transported substances: $\mathrm{FB}, \mathrm{NY}$, and horseradish peroxidase (HRP). In order to determine the adult pattern of these cells, rats received 0.2 to $0.3 \mu \mathrm{l}$ of $\mathrm{FB}$ or NY unilaterally in the motor cortex between PNDs 20 and 25 and were allowed to survive for 16 to $48 \mathrm{hr}$. Additional rats each received 0.2 to $0.3 \mu \mathrm{l}$ of HRP (a 40 to $50 \%$ solution in $2 \%$ dimethyl sulfoxide (DMSO) and $5 \%$ Nonidet (Lipp and Schwegler, 1980)) unilaterally in the motor cortex and had 18-, 24-, and 30-hr survival times. The neonatal pattern of ipsilaterally projecting cells also was determined with FB, NY, and HRP. On PND 7, several rats were injected unilaterally in the motor cortex with 0.05 to $0.15 \mu \mathrm{l}$ of $\mathrm{FB}, \mathrm{NY}$, or HRP. Three of the FB rats and all of the NY and HRP rats were sacrificed 12 to 24 $\mathrm{hr}$ later. The other FB-injected rats were allowed to survive until PND 20 to PND 25 for comparison with the adult pattern.

In the third group of experiments, we used double labeling techniques to determine in the same animal the patterns of neurons in the parietal cortex which project both contra- and ipsilaterally, i.e., those cells which have collateral processes. First, to determine the neonatal pattern of these dual projection neurons, $\mathrm{FB}$ was placed contralaterally at PND 7 and nuclear yellow was injected ipsilaterally at PND 7.5. These animals were sacrificed on PND 8. Second, in order to determine if neurons which had sent axons through the corpus callosum at 
TABLE I

Injection and sacrifice parameters

\begin{tabular}{|c|c|c|c|c|c|c|}
\hline \multirow{2}{*}{$\begin{array}{l}\text { No. of } \\
\text { Animals }\end{array}$} & \multicolumn{4}{|c|}{ Postnatal Age at Injection } & \multirow{2}{*}{ Survival Time } & \multirow{2}{*}{$\begin{array}{c}\text { Postnatal } \\
\text { Age at } \\
\text { Sacrifice }\end{array}$} \\
\hline & FB Contra" & NY Contra & FB Ipsi & NY Ipsi & & \\
\hline \multicolumn{7}{|l|}{ Contra } \\
\hline 3 & 7 & & & & $24-27 \mathrm{hr}$ & 8 \\
\hline 4 & 7 & & & & $13-18 \mathrm{~d}$ & $20-25$ \\
\hline 2 & 7 & & & & $33 \mathrm{~d}$ & 40 \\
\hline 3 & $20-25$ & & & & $36,48,72 \mathrm{hr}$ & $22-27$ \\
\hline 2 & 20,25 & 21,26 & & & $\begin{array}{l}\text { FB: } 6 \mathrm{hr}, 6 \mathrm{~d} \\
\text { NY: } 18,22 \mathrm{hr}\end{array}$ & 21,26 \\
\hline 2 & 7 & 21,24 & & & $\begin{array}{l}\text { FB: } 14-17 \mathrm{~d} \\
\text { NY: } 22 \mathrm{hr}\end{array}$ & 21,24 \\
\hline \multicolumn{7}{|l|}{ Ipsi } \\
\hline 3 & & & 7 & & $12,18,24 \mathrm{hr}$ & $7-8$ \\
\hline 2 & & & & 7 & $12,16 \mathrm{hr}$ & 7 \\
\hline 3 & & & 7 & & $13-18 d$ & $20-25$ \\
\hline 3 & & & 20,25 & & $24,48 \mathrm{hr}$ & 21,27 \\
\hline 2 & & & & 23 & $16,20 \mathrm{hr}$ & 23 \\
\hline \multicolumn{7}{|c|}{ Contra and ipsi } \\
\hline 4 & 7 & & & 7.5 & $\begin{array}{l}\text { FB: } 18-30 \mathrm{hr} \\
\text { NY: } 6,12,16,18 \mathrm{hr}\end{array}$ & 8 \\
\hline 7 & 7 & & & $20-25$ & $\begin{array}{c}\text { FB: } 13-19 \mathrm{~d} \\
\text { NY: } 6,8,12,16 \\
17,18,24 \mathrm{hr}\end{array}$ & $20-26$ \\
\hline 4 & $20-25$ & & & $21-26$ & $\begin{array}{l}\text { FB: } 40-60 \mathrm{hr} \\
\text { NY: } 16,16,17,18 \mathrm{hr}\end{array}$ & $21-26$ \\
\hline
\end{tabular}

"The abbreviations used are: contra, injection of dye into the parietal cortex contralateral to the cortical area examined; ipsi, injection of dye into the frontal cortex ipsilateral to the cortical area examined.

PND 8 but were located in "acallosal" areas at PNDs 20 to 25 project to the ipsilateral motor cortex after PND 20, we injected FB contralaterally at PND 7 and NY ipsilaterally between PNDs 20 and 25 in 7 rats and then allowed a 6- to $24-\mathrm{hr}$ survival time. Finally, in order to determine the pattern of neurons that project to both the contralateral and ipsilateral hemispheres in the adult rat, FB was placed contralaterally at PNDs 20 to 25 and NY was placed ipsilaterally at PNDs 21 to 26 in 4 rats. These rats had 16- to 18-hr survival times after the NY injections.

At sacrifice, the animals injected with fluorescent dyes were perfused transcardially with $0.1 \mathrm{M}$ cacodylatebuffered $(\mathrm{pH} 7.2) 0.9 \%$ saline and then with cacodylatebuffered $10 \%$ formalin. The brains were postfixed for 8 to $24 \mathrm{hr}$ in the buffered formalin and then were transferred to cacodylate-buffered $25 \%$ sucrose until they sank. They were sectioned at $30 \mu \mathrm{m}$ on a freezing microtome (to better visualize double labeled cells, a few sections from each brain were taken at $20 \mu \mathrm{m}$ ) and were mounted promptly from distilled water into chrome alum-coated slides. Within a few hours, the sections were examined on a Zeiss fluorescent microscope and appropriate sections were photographed (Zeiss filter package 4877029902). The photographed sections were later stained with toluidine blue to facilitate a comparison of similar cortical areas among animals. The animals injected with HRP were processed according to the technique of Mesulam (1976).

A few technical details regarding our use of fluorescent dyes should be mentioned. Fast blue has the fortuitous property of remaining within the cytoplasm of the cell which transports it for several weeks (up to about 5 weeks in the present study), thus enabling the investigator to follow a given labeled cell population over time. This property of fast blue was first utilized by G. M. Innocenti (1981) to demonstrate that a subpopulation of visual cortex neurons which project across the corpus callosum in the neonatal cat survive after losing this connection. While fast blue is known to cause tissue destruction at the injection site after long survivals, neither the Innocenti study nor our own has found any detrimental effects on the neuronal perikarya that accumulate and store the tracer. For example, the morphology of these neurons appears normal, and the dye does not appear to have leaked through the cell membrane into the surrounding milieu.

A typical FB-labeled cell is shown at high magnification in Figure 2A. The bright fluorescent granules in the cytoplasm are pink to white and accumulate in the cell as the survival time increases, thus aiding the identification of FB-labeled neurons. Nuclear yellow, as its name suggests, accumulates in the nucleus of the cell of origin. Typical NY-labeled neurons are shown in Figure $2 B$ and a neuron double labeled with FB and NY is shown in Figure 2C. Since NY is known to diffuse out of the nucleus and to be taken up by surrounding glial cells and eventually neurons (Bentivoglio et al., 1982), we have taken several precautions to avoid this artifact. First, for each type of experiment in which NY was used, we determined the optimal survival time for the labeling of neuronal nuclei in the barrel field area of parietal cortex 

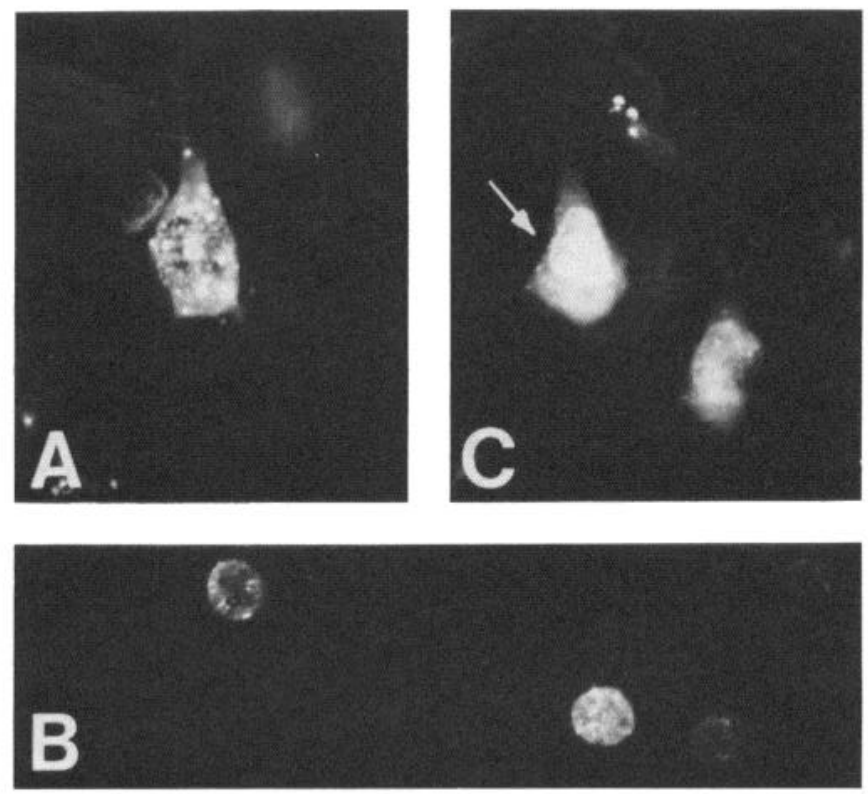

Figure 2. Typical appearance of neurons in rat parietal cortex when labeled with $(A)$ fast blue alone, $(B)$ nuclear yellow alone, or $(C)$ both fast blue and nuclear yellow (arrow).

without diffusion into surrounding glia. Second, we employed a number of the tissue-handling procedures suggested by Bentivoglio et al. (1980) to prevent diffusion of the tracer from the nucleus. We have found that, after cutting the sections, rapid mounting and drying of them onto the slide as well as expedient photographing of the tissue are especially important. Since, for each of the NY experiments reported below, we have taken our results from cases in which the NY is confined to neuronal nuclei and since, in each case, there are areas of the cortex in between the NY injection site and the labeled cells of origin which do not contain NY, we do not believe that these results are artifactual.

\section{Results}

We have found major developmental changes in the pattern of neurons of the rat parietal cortex which project via axon collaterals to both hemispheres. We will first describe the developmental pattern of cells which project contralaterally, next of those which project ipsilaterally, and finally of those which send axons to both hemispheres.

Figure $3 A$ demonstrates the pattern of labeled neurons in the parietal cortex of a PND 25 rat which had received an injection of FB in the contralateral cortex on PND 22. These FB-labeled neurons are located in all cortical laminae but are especially concentrated in laminae II-III and $\mathrm{Va}$ and are not present in all areas of the cortex. In particular, these neurons are not present (or are present only in small numbers) in an area known as the "barrel field" (arrows), which contains dense aggregates of granule cells and receives specific thalamocortical input (Killackey, 1973; Welker, 1976). This FB-labeled neuron pattern corresponds well to previously reported patterns of callosal neurons in the adult rat parietal cortex using the tracers true blue (O'Leary et al., 1981) and HRP (Wise and Jones, 1976; Ivy and Killackey, 1981).

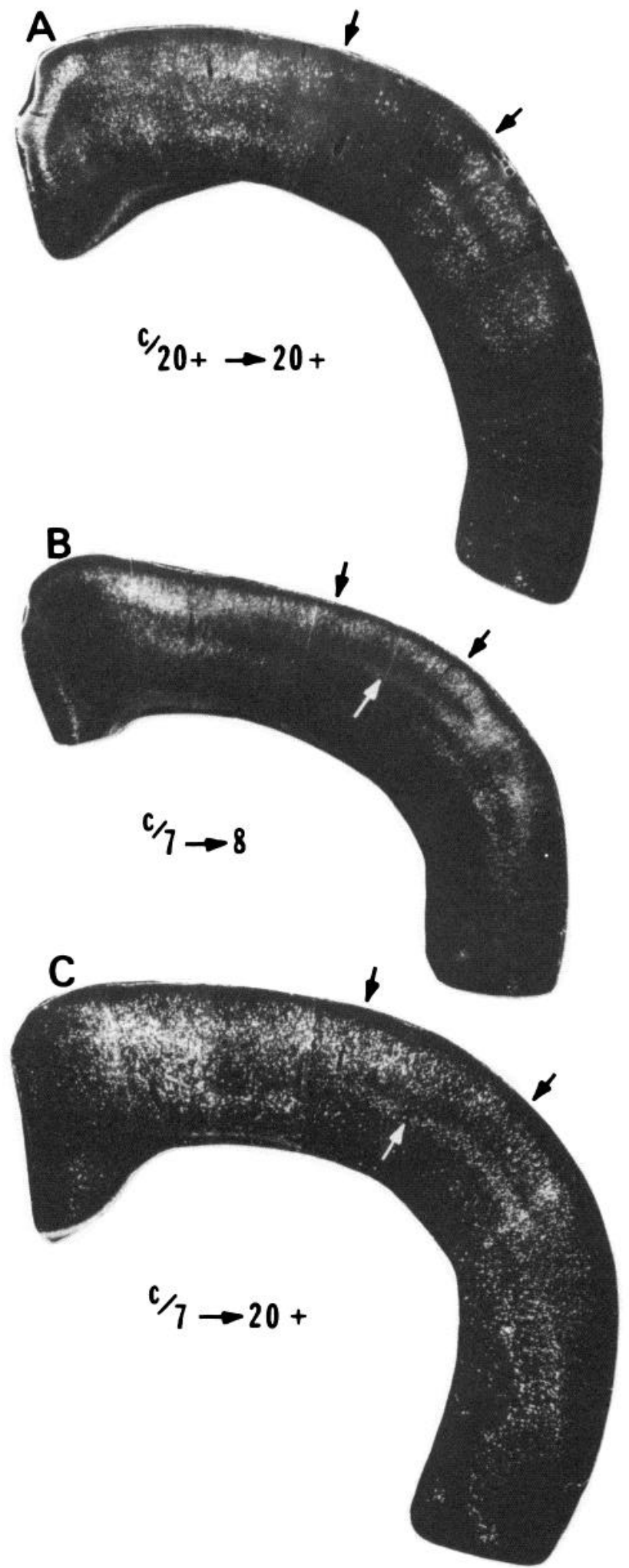

Figure 3. Montages of coronal sections through the rat parietal cortex showing the patterns of retrogradely labeled neurons after injections of FB contralaterally. $A$, The "mature" pattern of callosal projection neurons in a PND 23 rat after an injection of FB at PND 21. Note the relative absence of labeled cells in the barrel field area (black arrows). B. The "immature" pattern of callosal projection neurons in a PND 8 rat after an injection of FB $27 \mathrm{hr}$ earlier. Note the presence of labeled cells in a barrel field area (black arrows). The white arrow points to 
The neonatal callosal pattern is very different from that seen in the adult. Figure $3 B$ demonstrates the pattern of FB-labeled cells in a PND 8 rat resulting from a contralateral injection of FB at PND 7. Rather than being discretely distributed, the callosal projection neurons at this time are distributed continuously throughout all areas of the parietal cortex and are particularly prominent in layers II-III and Va in the barrel field (arrows). These results duplicate our previously reported findings using HRP (Ivy and Killackey, 1981). Next, in order to ascertain if the barrel field neurons which project across the corpus callosum in the neonate (but not the adult) die, we injected FB into 6 PND 7 rats and allowed them to survive until PNDs 20 to 40 , when the discrete adult pattern is established. Figure $3 C$ demonstrates that the cells which transported the FB on PND 7 are still present in the barrel field area (arrows) as well as in other acallosal areas of the cortex and, thus, that these cells have not died, confirming the report of O'Leary et al. (1981). For a direct comparison of the neonatal and adult patterns of callosal projection neurons in the same animal, we injected 2 rats contralaterally with FB on PND 7 and then injected NY in the same place between PNDs 20 and 25 . The cells containing NY were present in the discrete adult pattern and were essentially absent from the barrel field area, which contained numerous single FB-labeled neurons. In the known callosally projecting areas, the majority of the NY-labeled cells also were labeled with FB. However, within these caliosal areas there appeared to be more single FB- than single NYlabeled neurons. Thus, most neurons which had a demonstrable callosal projection at PND 20 to 25 also had one at PND 8, but the converse may not be the case. The areal pattern of labeled cells in these animals is indistinguishable from that shown in Figure $3 C$ and therefore is not illustrated. In the 2 rats receiving both FB and NY contralaterally after PND 20, numerous double labeled neurons were found in the adult callosal pattern. However, there were a few single FB- and single NY-labeled cells in callosal areas as well. The areal pattern of labeled cells in these rats is indistinguishable from that seen in Figure $3 A$ and therefore is not shown.

We next asked if the callosal projection neurons that are located in the barrel field area of the neonatal rat may either elaborate or maintain a projection elsewhere. A previous study (Akers and Killackey, 1978) had demonstrated by anterograde methods that neurons of the barrel field area send projections anteriorly to the motor cortex. In order to determine the precise laminar and areal origin of this projection, we utilized the retrograde transport of three separate tracers: FB, NY, and HRP. Our findings with all three are in agreement. A typical injection site is shown in Figure 4. The adult pattern of

cells in lamina Va. $C$, The "immature" pattern of callosal projection neurons in a PND 25 rat after an injection of FB 18 days earlier at PND 7. Note that many labeled neurons in lamina Va (white arrow) of the barrel field area (black arrows) are still present and thus have not died. In the shorthand labeling scheme, $c$ represents a contralateral injection site and the arrow points from the PND of injection to the PND of sacrifice.

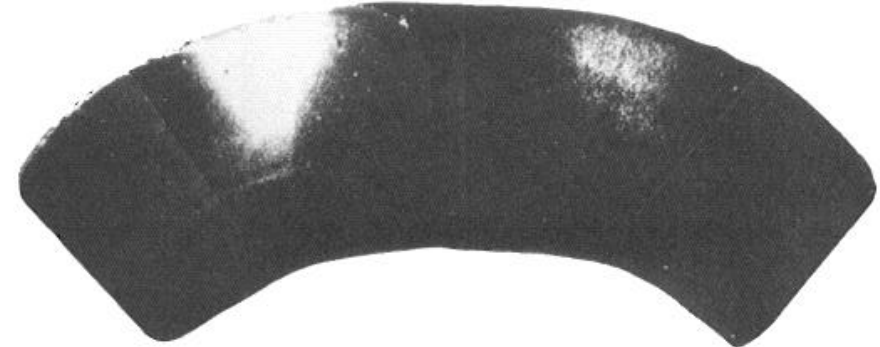

Figure 4. A typical injection site in the frontal cortex (left side). This rat was injected with $0.1 \mu \mathrm{l}$ of FB at PND 7 and was sacrificed $18 \mathrm{hr}$ later. Note the discrete pattern of labeled cells in the contralateral cortex. The resulting pattern of labeled neurons in the ipsilateral parietal cortex is shown in Figure $5 B$.

labeled cells resulting from an injection of FB into the ipsilateral motor cortex is shown in Figure $5 A$. In lateral portions of the cortex, the pattern of labeled cells resembles that of the callosal pattern, with concentrations of cells in laminae II-III and Va. However, in the barrel field area, where contralaterally projecting cells are absent, there are ipsilaterally projecting cells extending across lamina $\mathrm{Va}$ (arrows). We reasoned, then, that this population of ipsilateral projection neurons may have sent axons across the corpus callosum at earlier postnatal times, If so, did both the contra- and ipsilateral projections exist simultaneously, or did the ipsilateral projection develop subsequent to the loss of the callosal projection?

In order to answer these questions, we performed the following experiments. First, using FB, NY, and HRP, we demonstrated the pattern of ipsilaterally projecting cells at PND 8. Figure $5 B$ demonstrates this pattern in a rat injected with FB in the ipsilateral motor cortex at PND 7 and sacrificed $24 \mathrm{hr}$ later (the injection site for this animal is shown in Fig. 4). This neuronal labeling pattern was duplicated with NY and HRP and appears much like that of the adult. In particular, the cells in lamina $\mathrm{Va}$ of the barrel field area (arrows) are clearly labeled. This basic pattern was found to persist in animals injected with FB on PND 7 and allowed to survive until PNDs 20 to 25 (Fig. $5 C$ ). ${ }^{3}$ Next, in order to determine if the cells in layer $\mathrm{Va}$ of the barrel field area of the neonatal rat have dual projections across the corpus callosum and to the ipsilateral motor cortex, we injected FB in the contralateral hemisphere at PND 7 and NY in the ipsilateral motor cortex from 12 to $16 \mathrm{hr}$ later and then allowed a 6- to 18 -hr survival time. Following this procedure, there were numerous double labeled (FB and NY) neurons in lamina Va of the barrel field as well as in other cortical laminae and areas in which the ipsilaterally projecting cells are located. The areal pattern of labeled cells in these animals is indistinguishable from the pattern of single (FB) labeled callosal neurons at PND 8 (Fig. $3 B$ ) and thus is not shown. These results indicate that many parietal cortex neurons which project to the

\footnotetext{
${ }^{3}$ There appear to be more labeled neurons in the parietal cortex of animals injected in MSI at PND 7 than in those injected 2 weeks later. However, due to difficulties in comparing precise injection sizes in neonatal and adult rats, this finding requires further investigation.
} 

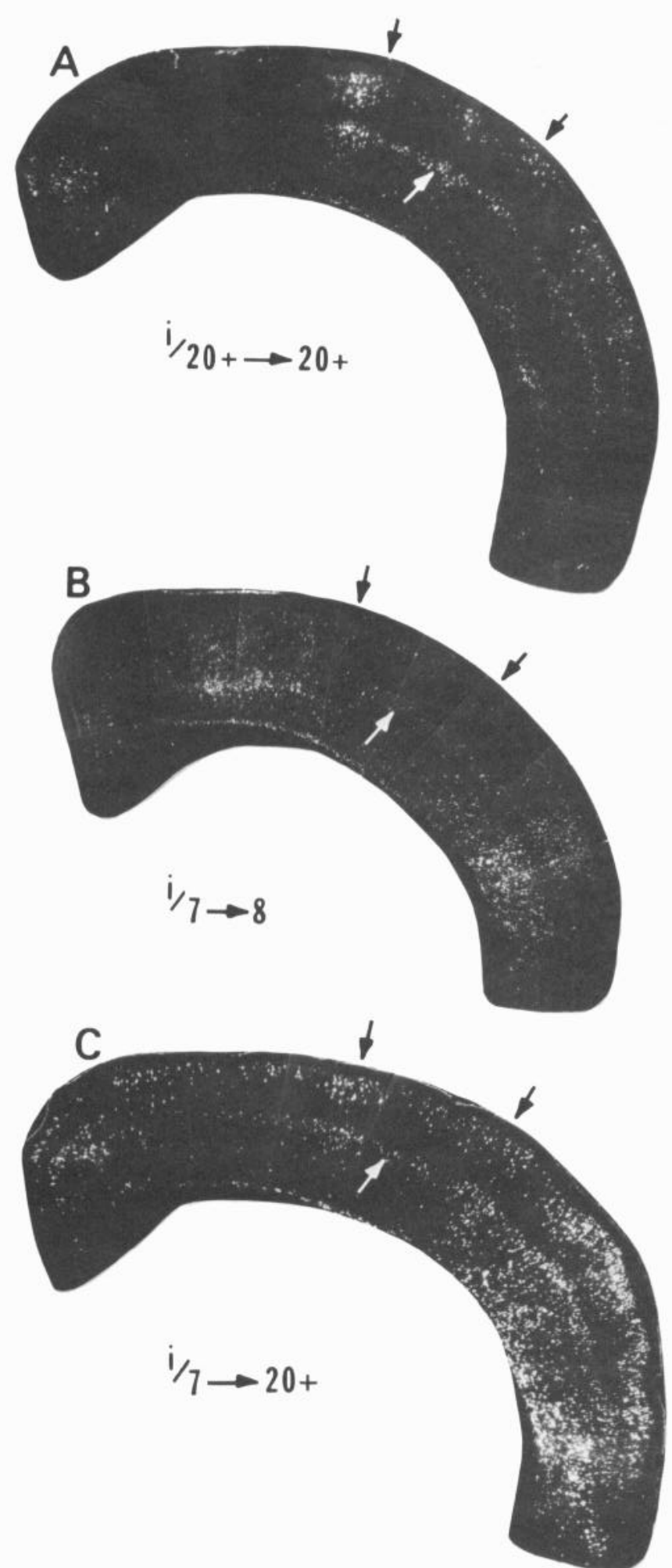

Figure 5. Montages of coronal sections through the rat parietal cortex showing the patterns of retrogradely labeled neurons after injections of FB in the ipsilateral frontal cortex. In each case, note the band of labeled cells in lamina Va (white arrow) of the barrel field area (black arrows). A, The pattern of ipsilateral projection neurons in a PND 27 rat after an injection of FB at PND 25. $B$, The pattern of ipsilateral projection neurons in a PND 8 rat after an injection of FB $24 \mathrm{hr}$ earlier. $C$, The pattern of projection neurons in a PND 25 rat after an injection of FB at PND 7. $i$, Ipsilateral injection site; the arrow points from the PND of injection to the PND of sacrifice. ipsilateral motor cortex at PND 8 also have collaterals which extend across the corpus callosum.

In order to demonstrate that at least some of the neurons-those in lamina $\mathrm{Va}$ of the barrel field arealose a contra- but maintain an ipsilateral process during development, two final experiments were performed. First, 7 rats received FB in one hemisphere at PND 7 and then received NY in the opposite motor cortex between PND 20 and PND 25. The overall pattern of labeled cells in the parietal cortex ipsilateral to the NY injection is shown in Figure $6 A$. Many of the neurons in lamina $\mathrm{Va}$ of the barrel field area (arrows) are double labeled (FB and NY). However, when both FB (placed contralaterally) and NY (placed ipsilaterally) are injected into PND 20 to 25 rats, the results are substantially different (Fig. 6B). As shown in Figure 7, the barrel field area contains almost exclusively single NY-labeled cells. In contrast, neurons containing $\mathrm{FB}$ are restricted to adult callosal zones. Double labeled cells appear strikingly fewer in general than seen after comparable injections in the neonatal rat.

Thus, a population of cortical neurons initially sends axonal processes to two very diverse targets and then later loses its projection to one of these areas. Before discussing the possible causes and implications of this phenomenon, two observations should be noted. First, in the fourth experiment, the reliability of the double labeling method was tested by placing both FB and NY in the contralateral hemisphere of the same PND 20 to 21 rat. Theoretically, all callosal projection neurons should be double labeled. However, while most of the neurons are indeed double labeled, single FB- and single NY-labeled neurons also appear. This may be due to small differences in the sites or amounts of the individual injections. There was no obvious difference in the number of single FBversus single NY-labeled neurons, which indicates that the FB injections (which took place $24 \mathrm{hr}$ earlier than the NY) did not damage axonal terminals or in some other way preclude later uptake of the NY. This control experiment serves to illustrate one of the difficulties inherent in quantifying the results of such double labeling experiments. In the present study, we circumvented the need for quantification by examining two populations of cells whose areal distributions overlap in lamina $\mathrm{Va}$ of the barrel field area in the neonatal rat but are largely nonoverlapping in the older rat.

A second noteworthy observation is that there appear to be more ipsilateral projection neurons after a PND 7 injection with a long survival (Fig. $5 C$ ) than in either the PND 8 (Fig. $5 B$ ) or the PND 22 rat (Fig. 5A). These discrepancies may be due to several factors. For example, it is possible that, in the neonatal rat, we are not visualizing all of the cells which transported FB, since the cell membranes are more fragile at this age (and therefore may have leaked their contents) and since there was less time for the cells to accumulate the FB than in the long surviving rats. Indeed, the contralateral projection neurons also appear fewer and less fluorescent in the neonatal than in the long surviving rat (compare Fig. 3, $B$ and $C$ ). Since all of our short and long surviving rats in experiment 5 are littermates which were injected at the same time and were selected at random for sacrifice, it is unlikely that there were differences in the size or place- 


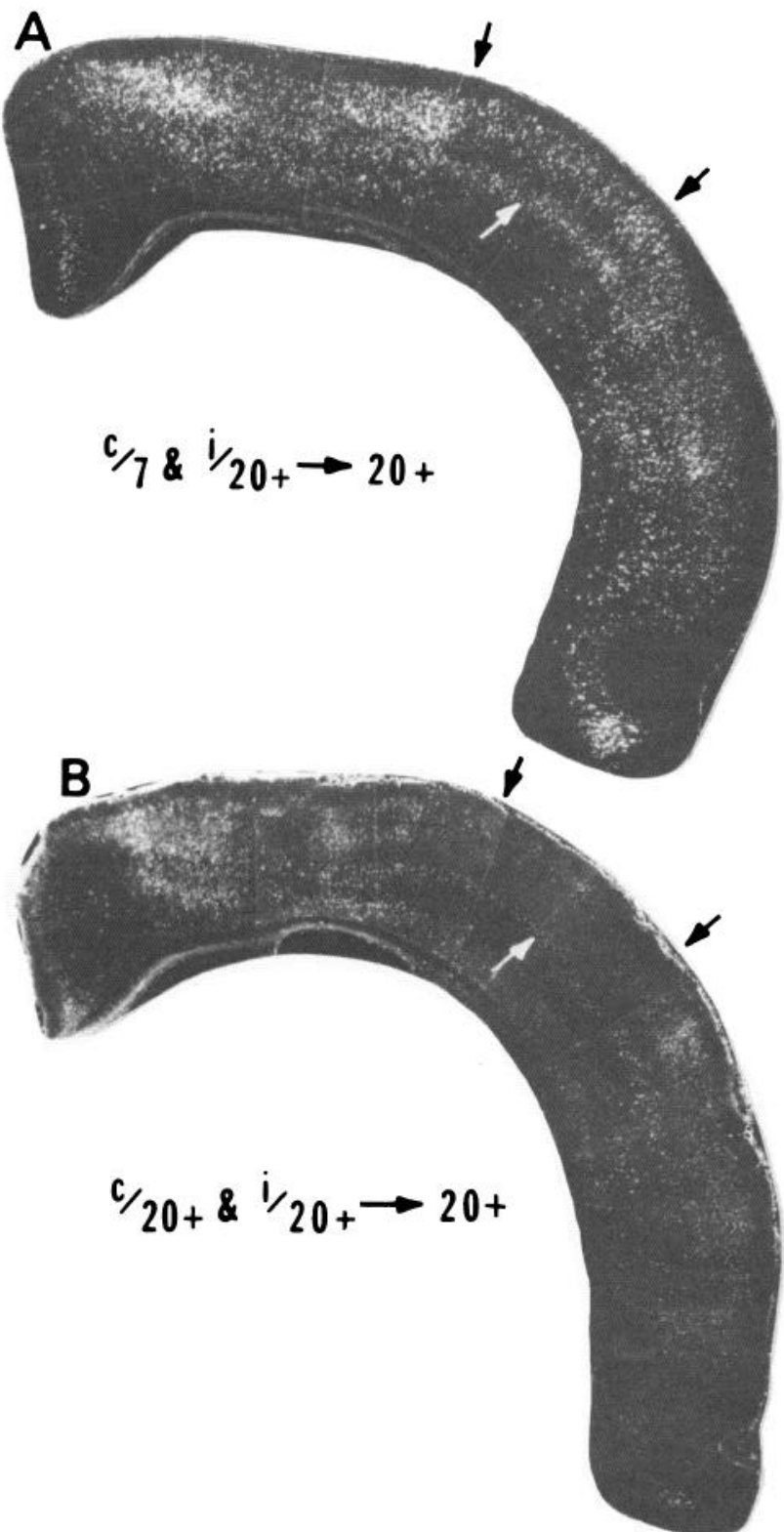

Figure 6. Montages of coronal sections through the rat parietal cortex showing the patterns of retrogradely labeled neurons after injections of FB contralaterally in the parietal cortex and NY ipsilaterally in the motor cortex. $A$, The pattern of labeled neurons resulting from an injection of FB at PND 7 and NY at PND 25. Many of the neurons in lamina Va (white arrow) of the barrel field area (black arrows) are labeled with both FB and NY. B, The pattern of labeled neurons resulting from an injection of FB at PND 24 and NY at PND 26. The neurons in lamina $\mathrm{Va}$ (white arrow) of the barrel field area (black arrows) are almost exclusively single labeled with NY as shown in Figure 7. $c$, Contralateral injection site; $i$, ipsilateral injection site; the arrow points from the PND of injection to the PND of sacrifice.

ment of injections in the two groups. Rather, it may be that young cortical neurons have exuberant ipsilateral, as well as contralateral, processes which are lost during later development. On the other hand, it is also possible that there are more labeled neurons after injection in the ipsilateral motor cortex at PND 7 and a long survival time because the tips of some axons that are growing out from parietal cortex to more anterior portions of frontal cortex can be labeled as they pass near the injection site during this developmental period. In any case, possible developmental changes in ipsilateral projections do not affect the conclusions of this study.

\section{Discussion}

During the development of both the visual cortex of the cat (Innocenti et al., 1977) and the parietal cortex of the rat (Ivy et al., 1979; Ivy and Killackey, 1981), the neurons that project across the corpus callosum are more widely distributed than in the adults of these species. Further, Innocenti (1981) and O'Leary et al. (1981) in the cat and rat, respectively, have demonstrated recently that a number of the cells that lose their callosal processes do not die. The implications of these findings are that the cells either elaborate or maintain other axons. In the present study, we demonstrate that this is indeed the case. In particular, we have found that a population of neurons in lamina $\mathrm{Va}$ of the barrel field area of parietal cortex projects at PND 8 both across the corpus callosum and to the ipsilateral motor cortex and that, as development proceeds, these cells lose their contralateral but maintain their ipsilateral axonal processes. Thus, we have shown that cortical neurons selectively eliminate major projections during development.

While the present experiments demonstrate that a number of cells survive the selective elimination of their contralateral processes, they do not rule out the possibility that other cells die. "Cell death" is a well documented phenomenon in the central nervous system (Cowan, 1973; Jacobson, 1978). Similarly, the present experiments do not rule out the possibility that the neonatal callosal projection neurons have still other, as yet undefined, collateral processes as well. Cortical neurons may project to a number of different targets initially but, as development proceeds, may stabilize selectively only one or a few of these projections as has been suggested for other developing neural systems (Changeux and Danchin, 1976). In this regard, it is interesting to note that FB injections into the contralateral parietal cortex at PND 7 result in more FB-labeled neurons in callosal areas at PND 20 or later than we find after similar injections at PND 20. Further, relatively few of these neonatally labeled callosal neurons are double labeled following our particular MSI injections of NY at PND 20 or later. It is not unlikely, then, that populations of neurons in adult callosal areas which projected across the corpus callosum at PND 7 have lost this contralateral process in favor of one to an ipsilateral area which was not injected in the present study. Indeed, lamina $\mathrm{Va}$ barrel field neurons in the area of vibrissae representation, in particular, seem to be most densely labeled following injections into the area of motor cortex in which the vibrissae are represented (Hall and Lindholm, 1974).

The exact cause for the loss of an axonal process remains to be determined. However, with regard to the present findings, we can suggest that there is some factor (or lack thereof) associated with the barrel field area (perhaps the dense thalamic input, the characteristic granule cell layer, or a factor set up earlier by the radial glia (Rakic, 1978)) which prevents the callosal axons from penetrating the cortical plate in this region (Ivy et al., 1979) and thus from stabilizing connections there. As a 


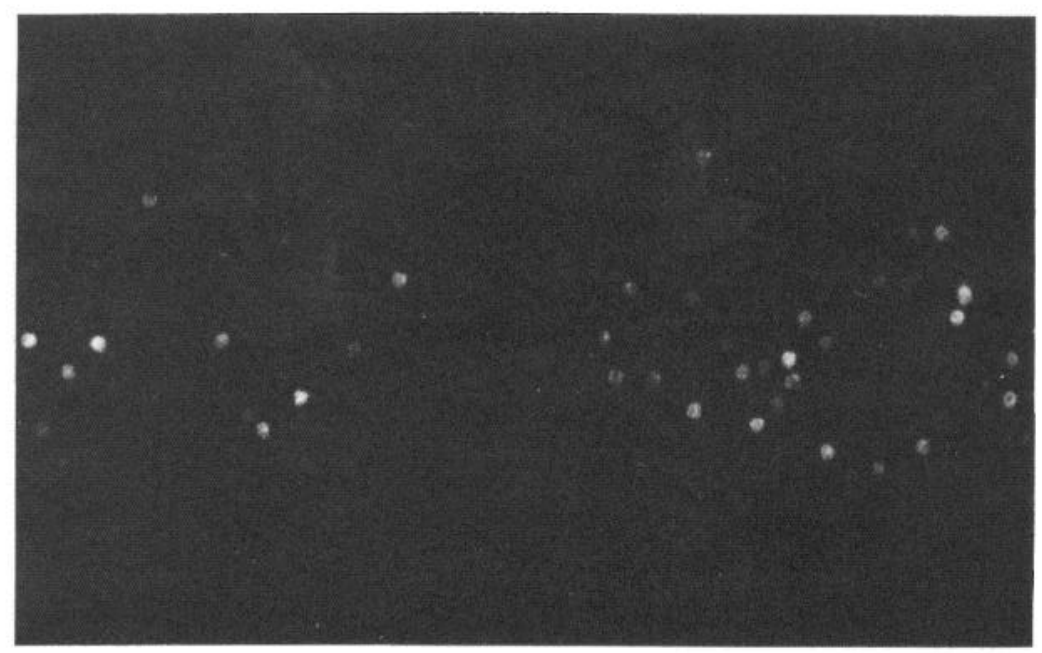

Figure 7. Single NY-labeled cells in lamina Va of the barrel field area taken from a section adjacent to that shown in Figure $6 B$.

consequence of this proposed stabilization failure, then, callosal projection neurons are somehow lost from the contralateral barrel field area. Some light may be shed on this phenomenon by experiments demonstrating that callosal connectivity patterns are altered by various surgical manipulations which cause an imbalance of visual input. For example, induced strabismus leads to an abnormally wide distribution of both callosal neurons (Innocenti and Frost, 1979) and callosal terminals (Lund et al., 1978) in the adult cat visual cortex. Similarly, unilateral eyelid suturing or enucleation in neonatal cats and hamsters also results in expanded callosal connections in the adult visual cortex (Innocenti and Frost, 1979; Rhoades and Dellacroce, 1980).

While the mechanisms underlying these changes are not clear, our results suggest that some cortical neurons may play an active role in selecting their targets by tentatively sampling potential target sites. Such a mode of establishing connectivity differs from that in most sensory systems, where a pattern of connectivity related to the periphery is replicated at each level of the neuraxis and, developmentally, order is established from the cell body toward the axon terminal and not vice versa. On the other hand, the process of establishing connectivity in the callosal and corticocortical projection neurons seems, at least superficially, to be analogous to the development of connectivity at the neuromuscular junction and in autonomic ganglia. In these systems, the neurons initially innervate a number of muscle fibers or ganglion cells but finally select only one or a few (see Purves and Lichtman, 1980, for a review). This analogy is, at present, only superficial, however, both because the events in these simpler systems have been analyzed at more molecular levels and because the potential targets of cortical neurons are separated by a much greater distance. In any case, the cortical neurons may have developed a target sampling strategy because they are not in direct contact with either the sensory or motor periphery. Indeed, they bridge the gap between the classical sensory and motor systems at the cortical level.

An initial "soft wiring" of cortical circuitry, such as that described in the present study, could help to explain the results of the experiments described above using altered visual input and could, in the normal animal, allow the benefits of early experience to aid in sculpting a cortical network which is better adapted to the animal's internal and external environments.

\section{References}

Akers, R. M., and H. P. Killackey (1978) Organization of corticocortical connections in the parietal cortex of the rat. $\mathrm{J}$. Comp. Neurol. 181: 513-538.

Bentivoglio, M., H. G. J. M. Kuypers, and C. E. CatsmanBerrevoets (1980) Retrograde neuronal labeling by means of bisbenzimide and nuclear yellow (Hoechst S 769121). Measures to prevent diffusion of the tracers out of retrogradely labeled neurons. Neurosci. Lett. 18: 19-24.

Changeux, J. P., and A. Danchin (1976) Selective stabilization of developing synapses as a mechanism for the specification of neuronal networks. Nature 264: 705-712.

Cowan, W. M. (1973) Neuronal death as a regulative mechanism in the control of cell number in the nervous system. In Development and Aging in the Nervous System, M. Rockstein, ed., pp. 19-41, Academic Press, New York.

Hall, R. D., and E. P. Lindholm (1974) Organization of motor and somatosensory cortex in the albino rat. Brain Res. 66 : 23-28.

Innocenti, G. M. (1981) Growth and reshaping of axons in the establishment of visual callosal connections. Science 212 : 824-827.

Innocenti, G. M., and D. O. Frost (1979) Abnormal visual experience stabilizes juvenile patterns of interhemispheric connections. Nature 280: 231-234.

Innocenti, G. M., L. Fiore, and R. Caminiti (1977) Exuberant projection into the corpus callosum from the visual cortex of newborn cats. Neurosci. Lett. 4: 237-242.

Ivy, G. O., and H. P. Killackey (1981) The ontogeny of the distribution of callosal projection neurons in the rat parietal cortex. J. Comp. Neurol. 195: 367-389.

Ivy, G. O., R. M. Akers, and H. P. Killackey (1979) Differential distribution of callosal projection neurons in the neonatal and adult rat. Brain Res. 173: 532-537.

Jacobson, M. (1978) Developmental Neurobiology, Plenum Press, New York.

Killackey, H. P. (1973) Anatomical evidence for cortical subdi- 
visions based on vertically discrete thalamic projections from the ventral posterior nucleus to cortical barrels in the rat. Brain Res. 51: 326-331.

Lipp, H. -P., and H. Schwegler (1980) Improved transport of horseradish peroxidase after injection with a non-ionic detergent (Nonidet P-40) into mouse cortex and observations on the relationship between spread at the injection site and amount of transported label. Neurosci. Lett. 20: 49-54.

Lund, R. D., D. E. Mitchell, and G. H. Henry (1978) Squintinduced modification of callosal connections in cats. Brain Res. 144: 169-172.

Mesulam, M. -M. (1976) The blue reaction product in horseradish peroxidase neurohistochemistry: Incubation parameters and visibility. J. Histochem. Cytochem. 24: 1273-1280.

O'Leary, D. D. M., B. B. Stanfield, and W. M. Cowan (1981) Evidence that the early postnatal restriction of the cells of origin of the callosal projection is due to the elimination of axonal collaterals rather than to the death of neurons. Dev. Brain Res. 1: 607-617.

Purves, D., and J. W. Lichtman (1980) Elimination of synapses in the developing nervous system. Science 210: 153-157.

Rakic, P. (1978) Neuronal migration and contact guidance in primate telencephalon. Postgrad. Med. J. 54: 25-40.

Rhoades, R. W., and D. D. Dellacroce (1980) Neonatal enucleation induces an asymmetric pattern of visual callosal connections in hamsters. Brain Res. 202: 189-195.

Welker, C. (1976) Receptive fields of barrels in the somatosensory neocortex of the rat. J. Comp. Neurol. 166: 173-190.

Wise, S. P., and E. G. Jones (1976) The organization and postnatal development of the commissural projection of the rat somatic sensory corlex. J. Comp. Neurol. 168: 313-344.

Wise, S. P., and E. G. Jones (1978) Developmental studies of thalamocortical and commissural connections in the rat somatic sensory cortex. J. Comp. Neurol. 178: 187-208. 